\title{
Intensive Care Unit
}

National Cancer Institute

\section{Source}

National Cancer Institute. Intensive Care Unit. NCI Thesaurus. Code C53511.

A health care facility unit that provides intensive care to critically ill patients and patients

with complex medical problems who require constant monitoring or special therapy. 